sciendo

\title{
Ser de Uma Maneira sem Ser Claramente dessa Maneira: um Problema para o Supervalorativismo
}

\author{
Ricardo Santos \\ Universidade de Évora LanCog
}

Disputatio Vol. 4, No. 34

December 2012

DOI: $10.2478 /$ disp-2012-0033

ISSN: 0873-626X 


\title{
Ser de Uma Maneira sem Ser Claramente dessa Maneira: um Problema para o Supervalorativismo
}

\author{
Ricardo Santos \\ Universidade de Évora e LanCog Group \\ BIBLID [0873-626X (2012) 34; pp. 823-849]
}

1 A diferença entre ser F e ser claramente F e o uso do operador «claramente» para resolver o sorites

Pode uma coisa ser de uma certa maneira sem ser claramente dessa maneira? Não parece difícil encontrar exemplos de casos que sugerem que essa é uma possibilidade que, em geral, estamos dispostos a aceitar. Um predicado vago tem, ou pelo menos pode ter, casos de fronteira: objectos a respeito dos quais não é claro se o predicado se lhes aplica ou não aplica. Perante um caso de fronteira de um predicado vago «F», se nos for perguntado «Isto é $F$ ?», a reacção típica é de hesitação: não sabemos o que responder, tanto «Sim» como «Não» parecem respostas possíveis ou legítimas e, no entanto, nenhuma delas parece ter justificação suficiente. Os exemplos tradicionais são «É isto um monte?», «Este homem é careca?» ou «Esta catedral é velha?», mas podemos também pensar em casos como «Foi esta acção corajosa?», «Este indivíduo é meu amigo?» ou «Este advogado é competente?». Mas, por vezes, se a pergunta for reformulada para «É claramente $F$ ?», a hesitação pode desaparecer e dar lugar a uma confiante resposta negativa: «Não, claramente $F$, não é». Nesses casos, rejeitamos a descrição da coisa como «claramente $F$, ao mesmo tempo que hesitamos a respeito da sua descrição como «F». É plausível interpretar este género de reacção como reveladora de uma predisposição geral para admitirmos que uma coisa que não é claramente $F$ pode, no entanto, ser $F$.

A admissão dessa possibilidade vai a par com a ideia de que, em geral, é preciso mais para ser claramente $F$ do que para ser $F$. E que, 
por isso, é natural esperar que haja menos coisas claramente $F$ do que coisas $F$ (numa série sorítica, por exemplo). E, se considerarmos que o advérbio «claramente» é iterável, será também natural esperarmos que haja ainda menos coisas claramente claramente $F$ do que coisas claramente $F$, e assim por diante.

$\mathrm{E}$, no entanto, pensadores importantes no estudo da vagueza (como Michael Dummett, Kit Fine, Rosanna Keefe, Roy Sorensen e outros) têm estado de acordo em julgarem que as coisas não podem ter uma propriedade sem terem claramente essa propriedade. Estará este seu acordo bem fundado?

Na medida em que assenta na diferença entre ser- $F$ e ser-claramente- $F$, a resposta à questão que estou a colocar depende crucialmente do significado da palavra «claramente». Alguns filósofos queixam-se que esta palavra tem um significado obscuro. Mas, por outro lado, há teorias que tentam representá-la por meio de um operador frásico $\Delta$ que, num sistema formalizado, recebe uma semântica específica e para o qual são propostas regras de inferência especiais.

A queixa quanto à obscuridade do operador «claramente» pode conduzir a que se repudie o seu uso numa teorização séria a respeito da vagueza. Há, no entanto, razões aparentemente fortes para justificar a necessidade de um tal operador. Uma razão que se destaca é a necessidade que temos do operador para resolver - de uma maneira bastante standard na filosofia contemporânea - o paradoxo de sorites. Passemos em revista, de um modo breve, o raciocínio para esse efeito.

É comum dizer-se que o que origina o sorites é o problema da vagueza: o paradoxo explora a vagueza de certos predicados como «monte», «careca», «alto» ou «velho», mostrando que, pelo menos aparentemente, essa vagueza nos conduz a contradições. Mas em que é que consiste essa vagueza e como é que ela conduz ao paradoxo? Quer dizer: qual é a característica que os predicados envolvidos têm que podemos identificar como a sua vagueza e que seria responsável pela incoerência que o paradoxo revela? A resposta habitual a esta pergunta é a de que essa característica é a que está representada na chamada premissa indutiva do sorites canónico, uma premissa que diz, por exemplo, que se uma pessoa não é velha quando já passaram $n$ segundos desde que nasceu, então ela também não é velha depois de terem passado $n+1$ segundos. Dizer que «velha» é um predicado 
vago equivaleria a dizer que este princípio é verdadeiro: um só segundo não pode fazer a diferença entre uma pessoa não-velha e uma pessoa velha. Isto seria a vagueza. Quanto à incoerência, ela torna-se manifesta se observarmos que, obviamente, uma pessoa velha se tornou velha ao ter vivido um certo número, grande mas finito, de segundos: ora, não é possível que tenha havido uma transição nessa série, mas que a transição não tenha ocorrido em nenhum ponto da série (dado que a série não é mais do que uma sucessão de pontos).

Uma saída standard para o problema consiste então em dizer que, neste raciocínio que nos conduz da vagueza até à contradição ${ }^{1}$, onde nos enganámos foi ao aceitarmos a premissa indutiva do argumento, concordando que um só segundo nunca pode fazer a diferença entre não-velho e velho. Embora esta afirmação nos tenha parecido ao início muitíssimo plausível, o que é facto é que o argumento mostrou que ela não pode estar certa. Como disse Crispin Wright, devemos encarar o argumento sorítico como uma reductio ad absurdum daquela premissa $^{2}$.

Até este ponto, muitos filósofos estão de acordo. Daqui em diante, porém, começam tipicamente a discordar a respeito de diversas questões subsequentes, como por exemplo: Devemos negar aquela premissa? Devemos considerar que ela é falsa ou devemos permanecer agnósticos acerca dela? Como se explica a forte tendência natural que temos para acreditar nela?

Menos polémica parece ser a questão de saber como é que a premissa deve ser revista, qual é o princípio que deve substituí-la. Recorde-se que começámos por aceitar a premissa porque pensávamos que ela seria a expressão adequada da vagueza do predicado. Se isso não é assim, como é então? Uma proposta bastante comum é a de dizer que aquilo a que o reconhecimento da vagueza de «velha» nos obriga é a aceitar este princípio ligeiramente modificado: se uma pessoa claramente não é velha quando já passaram $\mathrm{n}$ segundos desde que nasceu, então ela também não é claramente velha quando já passaram $\mathrm{n}+1$

${ }^{1}$ A contradição é entre o reconhecimento intuitivo de que uma pessoa com 90 anos (o que é um pouco mais do que 2840 milhões de segundos) é velha e a conclusão do raciocínio sorítico segundo a qual ela não é velha.

${ }^{2}$ Wright (1987) 234. Ver também Fine (1975) 139 («In fact, on the supertruth view, the second premiss is false.»). 
segundos. Não é entre não-velha e velha, mas sim entre claramente-não-velha e claramente-velha, que um só segundo nunca pode ser suficiente para fazer a diferença. «What the [...] paradox brings out», escreveu Wright, «is that, when dealing with vague expressions, it is essential to have the expressive resources afforded by an operator expressing definiteness or determinacy» ${ }^{3}$.

É evidente que este género de solução do sorites coloca muito peso sobre esta noção de ser claramente de uma certa maneira. De acordo com esta perspectiva, o uso desta noção faz toda a diferença entre o pensamento de que a vagueza é intrinsecamente incoerente e o pensamento de que a vagueza não é paradoxal em si mesma. Um filósofo que adopte esta perspectiva encontra-se sob uma pressão muito forte para que diga algo de iluminador acerca do significado de «claramente» e acerca da diferença entre ser velho e ser claramente velho. Ele parece ser a pessoa certa a quem perguntar: pode uma coisa ser de uma maneira sem ser claramente dessa maneira?

\section{Ideias centrais da teoria supervalorativista da vagueza}

O supervalorativismo fornece uma interessante semântica formal para linguagens vagas, no contexto da qual a questão que coloquei pode ser analisada de um modo mais rigoroso. Tomá-la-ei como referência. Nesta secção, farei uma apresentação preliminar das principais ideias e do programa filosófico que orienta o sistema formal supervalorativista - para que, na secção seguinte, possamos analisar o seu reflexo sobre o problema que nos interessa.

Tipicamente, o supervalorativismo toma a vagueza como um fenómeno semântico, que pode afectar qualquer categoria de expressões de uma linguagem, mas que, de modo paradigmático, se manifesta nalguns dos seus predicados. Um predicado vago é um predicado cujo significado é deficiente no seguinte sentido: as suas condições de aplicação são tais que, para certos objectos, a totalidade dos fac-

\footnotetext{
${ }^{3}$ Wright (1987) 229. Com o operador de clareza podemos também dizer (sem ascensão semântica, na própria linguagem-objecto) que $a$ é um caso de fronteira de $F$, assim: $\neg \Delta F a \wedge \neg \Delta \neg F$. E podemos expressar o fenómeno da vagueza de ordem superior, dizendo que $a$ é um caso de fronteira de um caso de fronteira de $F$ ou, de modo equivalente, que $a$ é um caso de fronteira de claramente- $F$, assim: $\neg \Delta \Delta F a \wedge \neg \Delta \neg \Delta F a$.
} 
tos relevantes a seu respeito não determina se elas se encontram ou não encontram cumpridas. Face a esta indeterminação, o supervalorativismo considera que, se um tal predicado for atribuído a um desses objectos, a frase declarativa resultante poderá não ser verdadeira nem falsa. O princípio da bivalência é, por isso, rejeitado. Mas a indeterminação característica dos predicados vagos não termina aqui, nesta admissão de que, para certos objectos, o predicado nem é verdadeiro nem é falso deles. Além disso, é também indeterminado que objectos são esses. O predicado é claramente verdadeiro de alguns objectos (pertencentes à sua extensão) e é claramente falso de alguns outros objectos (pertencentes à sua anti-extensão) e não é nem uma coisa nem outra de outros objectos ainda (os casos de fronteira, pertencentes à sua penumbra), mas é indeterminado onde é que uns terminam e os outros começam. É por isso difícil falar da extensão de um predicado vago, pelo menos da maneira como esta noção costuma ser entendida, na teoria dos modelos clássica, como um conjunto. Pois não há nenhuma vagueza na noção de conjunto. A identidade de um conjunto é constituída, extensionalmente, pelos objectos que são seus membros - de tal modo que, se não estiverem definidos os objectos que lhe pertencem, não está dado nenhum conjunto. Para lidar com este problema, a ideia-chave do supervalorativismo consiste em atribuir a cada predicado vago, em vez de uma extensão definida, um leque de extensões possíveis. Estas extensões possíveis correspondem a maneiras aceitáveis de tornar o predicado preciso, ou seja, correspondem a precisões aceitáveis do predicado. Estas precisões são aceitáveis na medida em que são compatíveis com o significado do predicado e com os factos extra-linguísticos ${ }^{4}$. Nenhuma delas tem qualquer privilégio sobre as outras. Alguns objectos são tais que o predicado é verdadeiro deles numas precisões e falso noutras ${ }^{5}$. Mas haverá objectos dos quais o predicado é verdadeiro em todas as preci-

${ }^{4} \mathrm{O}$ leitor perspicaz já terá inferido que «aceitável» é aqui um predicado vago da metalinguagem. Caso contrário, o «leque de extensões possíveis» seria um conjunto de conjuntos e estaria determinado, para cada objecto, se pertence ou não pertence a algum desses conjuntos (ou a todos ou a nenhum).

${ }^{5}$ Registe-se o pressuposto de que as precisões tornam o predicado completamente preciso, sem casos de fronteira. Ou seja, nesta versão da teoria, as precisões são interpretações clássicas, bivalentes. 
sões - e aí dizemos que o predicado é super-verdadeiro desses objectos; de outros objectos, o predicado será super-falso, quer dizer, falso em todas as precisões. E a tese fundamental do supervalorativismo é a de que, para uma linguagem com predicados vagos, a noção adequada de verdade é esta noção definida de super-verdade, ou verdade em todas as precisões, entendidas como maneiras aceitáveis de tornar a linguagem precisa.

Um dos pontos fortes do supervalorativismo é a sua promessa de conciliar a existência de falhas de valor de verdade com o respeito pelas chamadas «conexões de penumbra»e pelas verdades daí resultantes. Este termo foi cunhado por Kit Fine (1975) para referir a existência de relações lógicas entre expressões vagas. Suponhamos que um certo livro tem uma cor uniforme, mas que está na fronteira entre o verde e o azul. Em certas precisões o livro conta como verde, noutras conta como azul. Mas não há nenhuma precisão aceitável em que o livro possa ser simultaneamente verde e azul. Quer dizer, a conjunção «o livro é verde e azul» é falsa, apesar de ser composta por sub-frases que são ambas indefinidas. Por outro lado, reconhecemos a disjunção «o livro é verde ou azul» como verdadeira, porque em cada maneira aceitável de precisar os predicados o livro cairá sempre na extensão de um ou na do outro. E se houver um segundo livro, situado na mesma fronteira cromática, mas ligeiramente mais azulado que o primeiro, reconheceremos como verdadeira a condicional «se o primeiro livro é azul, então o segundo livro é azul». O supervalorativismo atribui grande importância a estas verdades de penumbra. A primeira lição que retira delas é que, por causa das conexões existentes entre eles, os predicados de uma linguagem não podem ser precisados um a um, mas têm de sê-lo sempre em conjunto. Cada precisão é uma precisão da linguagem como um todo. Além disso, para ser aceitável, uma precisão tem de respeitar ou de ser fiel aos significados originais da linguagem vaga. Por exemplo, se António for um caso claro de um homem velho, nenhuma precisão de «velho» será aceitável se nela a frase «António é velho» não for verdadeira. O mesmo vale para as verdades de penumbra: elas correspondem a condições que as precisões da linguagem têm de respeitar para serem aceitáveis. Pois uma precisão em que um livro ligeiramente mais azulado do que um livro azul não fosse azul estaria a violar o significado original da palavra «azul». E o mesmo aconteceria com uma precisão 
na qual um livro (todo) azul fosse também (todo) verde.

Uma outra lição que o supervalorativismo retira das verdades de penumbra é que elas mostram que, numa linguagem vaga, as conectivas proposicionais funcionam de uma maneira que é incompatível com a ideia - que é central na semântica da lógica clássica - de que elas expressam funções de verdade. Quando se abandona a bivalência e se admite que algumas frases atómicas podem ser semanticamente indefinidas, precisamos de alguma maneira alternativa para lidar com os compostos lógicos que as incluem. Para esse efeito existem propostas de novas tabelas de verdade que estendem as bem conhecidas tabelas da lógica clássica para um terceiro valor, além do verdadeiro e do falso (como, por exemplo, as chamadas tabelas fortes de Kleene). O supervalorativismo alega que as conexões de penumbra mostram que nenhuma tabela dessas pode ser correcta, pois diferentes compostos, cujos elementos têm os mesmos valores, podem receber valores diferentes. Para verificar isso, basta comparar os exemplos anteriores com estes: «o livro é verde ou interessante» (supondo que ele também é um caso de fronteira de um livro interessante) e «se o segundo livro é azul, então o primeiro livro é azul» (invertendo a ordem das frases componentes); apesar de terem a mesma forma e componentes com o mesmo valor, estas frases não são verdadeiras. Precisamos, portanto, de uma semântica não-verofuncional para as constantes lógicas, que seja compatível com o reconhecimento das verdades (e das falsidades) de penumbra. A solução proposta pelo supervalorativismo consiste em começar por avaliar as frases - atómicas e moleculares - em cada uma das precisões (como estas são interpretações clássicas, podemos usar as velhas tabelas bivalentes) e, depois, definir cada frase como (i) super-verdadeira, (ii) super-falsa ou (iii) indeterminada consoante ela seja (i) verdadeira em todas as precisões, (ii) falsa em todas as precisões ou (iii) verdadeira numas precisões e falsa noutras. Uma disjunção como «o livro é verde ou interessante» será verdadeira nalgumas precisões (a saber, nas precisões em que o livro caia na extensão de «verde» ou caia na extensão de «interessante») e falsa noutras (a saber, nas precisões em que o livro seja azul e desinteressante) e, por isso, é indeterminada. Já a disjunção «o livro é verde ou azul» será verdadeira em todas as precisões (pois, devido à conexão entre os dois predicados, numas precisões o livro será verde mas não azul, noutras será azul mas não verde e em 
nenhuma será nem verde nem azul) e, por isso, será reconhecida pela semântica como super-verdadeira.

O supervalorativismo também fornece uma resposta interessante à questão de saber qual é a lógica correcta para os raciocínios que efectuamos numa linguagem vaga. A lógica clássica foi desenvolvida com o objectivo de formalizar o raciocínio matemático. Os seus fundadores pretendiam construir um modelo formal daquilo que, de modo informal, julgavam ser o raciocínio matemático correcto (e neste seu juízo informal enfrentaram a oposição dos intuicionistas, para quem há formas não-construtivas de raciocínio matemático que não devem ser aceites como correctas). Mas na linguagem matemática não existe vagueza (ou, pelo menos, assim parece). Por isso, não temos à partida nenhuma garantia de que a lógica clássica seja uma lógica apropriada para linguagens vagas. $\mathrm{O}$ argumento do sorites (que informalmente reconhecemos como válido) é válido na lógica clássi$\mathrm{ca}$, mas isso por si só significa pouco. Pois ele poderá igualmente ser válido noutras lógicas, não-clássicas (por exemplo, ele também é válido na lógica intuicionista). No entanto, não devemos menosprezar as dificuldades envolvidas em abandonar a lógica clássica. Trata-se de uma lógica simples mas poderosa, que é bem conhecida, para a qual existem sistemas dedutivos (como a dedução natural) comprovadamente correctos e completos; e, como sabemos, é a lógica da matemática clássica e, também por essa via, de toda a ciência moderna (ou de quase toda). Além disso, se vamos discutir uma possível mudança de lógica, que lógica é que vamos usar nessa discussão?

Perante isto, uma teoria que prometa esclarecer o funcionamento de uma linguagem vaga e fazê-lo de uma maneira que permita preservar a lógica clássica poderá ser particularmente bem-vinda. E, de certo modo, é isso (ou quase) o que o supervalorativismo promete. A semântica que propõe não coincide, nem é compatível, com a semântica da lógica clássica - basta notar que a bivalência é rejeitada. Mas esta semântica não-clássica, se não acrescentarmos nenhuma constante lógica nova à linguagem, acaba por validar todas as regras de inferência da lógica clássica. Os modelos da semântica supervalorativista têm uma estrutura diferente dos modelos clássicos e as fórmulas da linguagem formal são avaliadas nesses modelos com um de três valores - super-verdadeiras, super-falsas ou indeterminadas. Um argumento é então definido como válido (a sua conclusão é uma 
consequência semântica das premissas) quando é preservador da super-verdade em todos os modelos supervalorativistas. Acontece que esta noção de validade (e a relação de consequência que lhe subjaz) coincide em extensão com a noção de validade da lógica clássica: são exactamente os mesmos argumentos que são declarados válidos por uma e por outra (e as respectivas classes de verdades lógicas também coincidem). Isto é assim porque a super-verdade (aquilo que um argumento válido tem de preservar) foi definida como verdade em todas as precisões; e as precisões que compõem um modelo supervalorativista mais não são do que modelos clássicos (com o mesmo domínio). Um argumento preserva a super-verdade nos modelos supervalorativistas se e somente se ele preserva a verdade nos modelos clássicos.

Esta conservação da lógica clássica tem algumas consequências importantes com que o supervalorativismo tem de lidar. Uma delas é forçar-nos a afirmar a negação da premissa indutiva do argumento sorítico (uma vez que esta premissa, juntamente com uma outra que é totalmente insuspeita, conduz a uma conclusão manifestamente falsa). Ora, na lógica clássica, essa negação é equivalente à seguinte frase existencial: Existe um número $\mathrm{n}$ tal que António não é velho com $\mathrm{n}$ segundos de idade e António é velho com $\mathrm{n}+1$ segundos de idade. Ao afirmarmos isto parece que estamos a afirmar que há, na vida de António, um segundo muito especial, com a passagem do qual ele muda subitamente de não-velho para velho. $O$ filósofo supervalorativista tem de dar-nos uma justificação satisfatória para o facto de fazer esta afirmação - e esta é uma das suas tarefas mais difíceis ${ }^{6}$. Várias vias de justificação têm sido tentadas. Uma delas aponta para o facto de que, embora aquela frase existencial seja verdadeira (i.e., super-verdadeira, nos termos do supervalorativista), ela não tem nenhuma instância que seja (super-)verdadeira, quer dizer, não há nenhum número $j$ referido por um termo «k» tal que a frase «António não é velho com $k$ segundos de idade e António é velho com $k+1$ segundos de idade» seja (super-)verdadeira. De facto, na semântica supervalorativista, uma afirmação existencial $\exists x F_{x}$ pode ser verdadeira sem que nenhuma das suas instâncias o seja (e, de modo análogo, uma disjunção pode

${ }^{6}$ Veja-se a discussão deste aspecto em Keefe (2000) 183 e ss., confrontando com Williamson (1994) 153-154. 
ser verdadeira sem que nenhum dos seus membros seja verdadeiro). Isso acontece quando todas as precisões têm um objecto que satisfaz $F_{x}$, mas, porque esse objecto muda de umas precisões para as outras, não há nenhum que satisfaça $F_{X}$ em todas as precisões. Alguns autores objectam que isto não é uma leitura aceitável do quantificador existencial. Quando alguém afirma que existe um objecto que é $F$, uma reacção natural é perguntarmos «Qual?»; mas, a esta pergunta, o supervalorativista responde-nos dizendo que não é nenhum em particular. Há situações em que sabemos (por via inferencial) que existe um $F$, mas somos incapazes de identificar um objecto específico que seja $F$. A explicação normal para essas situações é o carácter limitado do nosso conhecimento. Mas a incapacidade que o supervalorativista aqui nos atribui não é devida à ignorância. Não há ignorância, neste caso, porque o que ele diz é que não há aqui nenhum facto para ser conhecido. Não há nenhum objecto para o qual o significado das palavras e os factos extra-linguísticos juntos determinem que ele seja $F$. No entanto, alegadamente, em certos casos, esses mesmos significados e factos determinam que existe um $F$.

Uma outra consequência importante da conservação da lógica clássica para o supervalorativismo é o abandono do princípio descitativo da verdade. Para a sua noção privilegiada de verdade - que é a noção de super-verdade, definida como verdade em todas as precisões -, não vale o princípio que diz que devemos aceitar todas as frases com a mesma forma que esta: «A neve é branca» é (super-)verdadeira se e somente se a neve é branca. Pois, para o supervalorativismo, apesar de António ser um caso de fronteira de homem velho, é verdade que ele ou é velho ou não é velho. Mas, se ele é velho, segue-se pelo princípio descitativo que a frase «António é velho»é verdadeira. E se ele não é velho, segue-se pelo princípio descitativo (e pela definição de falsidade como verdade da negação) que «António é velho» é falsa. Teríamos então de concluir que «António é velho» ou é verdadeira ou é falsa, apesar de o supervalorativista pretender que ela não é nem uma coisa nem a outra. O princípio descitativo forçaria o supervalorativista a aceitar a bivalência; e, por isso, ele rejeita-o. A sua semântica está de acordo com esta rejeição. Pois, nas precisões em que António conta como velho, a condicional «Se António é velho, então a frase "António é velho" é super-verdadeira» tem antecedente verdadeira e consequente falsa (uma vez que há outras precisões em que ele conta 
como não-velho); ora, uma condicional que é falsa nalgumas precisões nunca poderá ser aceite como super-verdadeira.

A conservação da lógica clássica tem, como podemos ver, custos elevados para o supervalorativista. Além disso, é algo que ele não pode manter completamente, ou até ao fim. Pois, como vimos na secção anterior, ele precisa de dotar a linguagem de meios para expressar a noção de ser claramente de uma certa maneira; e fá-lo adoptando um operador $\Delta$, gramaticalmente análogo à negação, que se prefixa a qualquer fórmula $X$ para gerar uma fórmula $\Delta X$. O supervalorativista encara este operador como uma maneira de representar, na linguagem-objecto, a noção metalinguística de super-verdade $^{7}$. Afirmar $\Delta F a$ é, para ele, uma maneira de traduzir a afirmação metalinguística de que «Fa» é super-verdadeira, ou de que $a$ cai na extensão de $\langle F \gg$ em todas as precisões, ou de que $a$ é um caso claro de $\langle F\rangle$. Na semântica formal, o operador $\Delta$ é tratado como uma nova constante lógica, cujas condições de verdade estão de acordo com esse entendimento intuitivo do seu significado. Na linguagem original, uma fórmula $X$ é super-verdadeira quando é verdadeira em todas as precisões. Então, na linguagem enriquecida, diremos que, em cada precisão (de um modelo), $\Delta X$ é verdadeira se e somente se $X$ é verdadeira em todas as precisões (desse modelo).

Com estas condições de verdade, podemos observar que, para todo o modelo $M$, se uma fórmula $\Delta X$ é super-verdadeira em $M$, então $X$ é igualmente super-verdadeira em $M$; e, conversamente, se $X$ é super-verdadeira em $M$, então $X$ é verdadeira em todas as precisões de $M$ e, por isso, $\Delta X$ também é verdadeira em todas essas precisões, pelo que $\Delta X$ é super-verdadeira em $M$. Nesta semântica, $X$ e $\Delta X$ implicam-se mutuamente. No entanto, apesar desta implicação recíproca, $\Delta$ não é um operador redundante e $X$ e $\Delta X$ não são substituíveis uma pela outra salva veritate em todos os contextos; pois, por exemplo, $\neg \Delta X$ pode ser super-verdadeira sem que $\neg X$ o seja (isso acontece nos modelos em que $X$ é indeterminada). Mas, então, temos que $X$ implica $\Delta X$, mas $\neg \Delta X$ não implica $\neg X$, contrariamente ao que diz a regra da contraposição da lógica clássica (viz., se uma fórmula $Y$ se infere de $X$ e de certas premissas e suposições, então $\neg X$ pode

\footnotetext{
${ }^{7}$ Como se trata de um operador, e não de um predicado, ele não permite gerar frases mentirosas (que afirmam a sua própria não-verdade).
} 
inferir-se de $\neg Y$ e dessas premissas e suposições). Além disso, apesar de $X$ implicar $\Delta X$, há modelos nos quais a condicional $X \rightarrow \Delta X$ não é super-verdadeira. Mas uma das regras da lógica clássica (a introdução da condicional) diz precisamente que, se inferimos $Y$ a partir de $X$ e de certas premissas e suposições, podemos inferir a condicional $(X$ $\rightarrow Y$ ) a partir dessas premissas e suposições. Isto mostra que, com a adição do operador $\Delta$, a semântica supervalorativista deixou de conservar a lógica clássica: há novas relações de consequência (pois as inferências de $\Delta X$ para $X$ e vice-versa não são classicamente válidas) e há relações de consequência clássica que se perdem (em argumentos que envolvem o uso do novo operador).

Além da contraposição e da introdução da condicional, há mais duas regras fundamentais da lógica clássica que falham nesta semântica supervalorativista enriquecida com o operador de clareza: a eliminação da disjunção e a introdução da negação (ou reductio ad absurdum) ${ }^{8}$. Como contra-exemplo da primeira, temos que $(\Delta X \vee \Delta \neg X)$ se segue de $X$ e também se segue de $\neg X$, mas não se segue de $(X \vee \neg X)$. Como contra-exemplo da segunda, temos que, apesar de $(X \wedge \neg \Delta X)$ ter como consequência a contradição $(\Delta X \wedge \neg \Delta X)$, a negação $\neg(X$ $\wedge \neg \Delta X$ ) (que é equivalente a $X \rightarrow \Delta X$ ) não é super-verdadeira em todos os modelos.

Estes contra-exemplos de regras dedutivas clássicas que são centrais nos nossos hábitos de raciocínio devem fazer-nos parar para pensar. É verdade que, à luz da semântica supervalorativista, estas formas de raciocínio não são válidas. Mas estará o problema nas formas de raciocínio ou estará ele antes na própria semântica formal apresentada? Quando estamos a avaliar o supervalorativismo enquanto teoria da vagueza, não pode ser a sua semântica formal a ditar quais são os raciocínios que contam como correctos. A nossa avaliação intuitiva de raciocínios com termos vagos precisa de ser justificada independentemente do sistema formal. A este nível, não há substituto para a discussão filosófica.

${ }^{8}$ Cf. Williamson (1994) 151-2. 


\section{A tese supervalorativista da incompatibilidade entre $\mathrm{X}$ e $\neg \Delta \mathrm{X}$ em discussão}

Depois desta breve revisão dos principais traços da semântica supervalorativista para uma linguagem de primeira ordem com predicados vagos, e da sua lógica, regresso à minha questão principal de saber se uma coisa pode ser de uma maneira sem ser claramente dessa maneira - e à resposta negativa que a teoria supervalorativista standard lhe dá. De facto, de acordo com esta teoria, para toda a frase declarativa $X$, seria incoerente afirmar ao mesmo tempo «X» e «Não é o caso que claramente $X »$. Por outras palavras, o supervalorativista julga que, por razões lógicas, nenhuma frase que tenha a forma « $X$ e não é o caso que claramente $X$ » (como, por exemplo, a frase «António é velho, mas não é claramente velho») pode ser verdadeira. Poderemos chamar a isto a tese da incompatibilidade ${ }^{9}$. E agora a questão é: por que razão deveríamos aceitar esta tese?

A tese da incompatibilidade está bem reflectida na semântica formal supervalorativista. Pois, suponhamos (para reductio) que há um modelo $M$ no qual $(X \wedge \neg \Delta X)$ é super-verdadeira. Então, $(X \wedge \neg \Delta X)$ é verdadeira em todas as precisões de $M$. Pelas regras da conjunção e da negação, isso implica que (i) $X$ é verdadeira em todas as precisões de $M$ e que (ii) $\Delta X$ é falsa em todas as precisões de $M$. Mas (i) satisfaz as condições de verdade de $\Delta X$ (quer dizer, se $X$ é verdadeira em todas as precisões, então $\Delta X$ é também verdadeira em todas as precisões), contradizendo (ii). Concluímos então que não há nenhum modelo no qual $(X \wedge \neg \Delta X)$ seja super-verdadeira. Esta conformidade da semântica com a tese da incompatibilidade é o que seria de esperar. Neste contexto, ela não serve de justificação para a tese, pois o que queremos avaliar é se esta semântica formal fornece um modelo adequado de como funciona uma linguagem vaga.

Uma coisa que o supervalorativista poderia estar tentado a apresentar como razão para rejeitarmos a possibilidade de $X \mathrm{e} \neg \Delta X$ serem

9 Wright (2010) chama-lhe "o Princípio de Dummett": "We can call Dummett's Principle the thesis that there are no truthful instances of the conjunctive form: P but not definitely P. As will emerge later, there is actually considerable pressure against the principle” (524n3). A possibilidade de rejeitar este princípio é considerada na p. 540 . 
conjuntamente verdadeiras é que, de $(X \wedge \neg \Delta X)$, segue-se uma contradição ${ }^{10}$ : adoptando tal conjunção como premissa, podemos derivar $\Delta X$ e também $\neg \Delta X$. Mas é evidente que ele deriva esta contradição usando uma regra de introdução do operador $\Delta$ que o autoriza, a partir de $X$ (apoiada, talvez, em certas premissas e suposições), a derivar $\Delta X$ (apoiada nessas mesmas premissas e suposições). Mas aceitar esta regra equivale a julgar que não é possível que $X$ seja verdadeira e $\Delta X$ não o seja - e isto implica aceitar a tese da incompatibilidade. A regra e a tese são solidárias e não podem justificar-se uma à outra.

Haverá razões independentes para aceitar esta regra de introdução do operador $\Delta$ ? Kit Fine (2008: 120) tenta fornecer uma justificação para ela. Primeiro, ele estabelece uma conexão entre as noções de incompatibilidade e de compromisso (entendidas ambas num «sentido conceptual amplo»): a asserção de diversas proposições é conjuntamente incompativel se e somente se essa asserção nos compromete com uma contradição. Em seguida, coloca a questão de saber se esta relação de compromisso está de acordo com a regra de introdução de $\Delta$ :

«[...] in asserting (or in being prepared to assert) a proposition $\mathrm{P}$, am I thereby committed to its being definitely the case? Surely I am. For the relevant notion of definiteness is one in which it is cognate with the notion of a borderline case. To say that $\mathrm{x}$ is definitely $\mathrm{F}$ in the relevant sense is to say that it is F and not a borderline case of F. But now the assertion that a man is bald, let us say, will surely commit one to his not being a borderline case of a bald man. For how could one sensibly assert that a given man is bald and yet not thereby be willing to deny that he is a borderline case of a bald man? Given that this is so, it will then follow directly from the above equivalence that the man is definitely bald; and the rule of D-Introduction will have been vindicated.»

A via mais habitual é explicarmos a noção de caso de fronteira em termos da noção de clareza, dizendo que $x$ é um caso de fronteira de $F$ se e somente se $x$ nem é claramente $F$ nem é claramente não- $F$. Neste trecho, Fine apresenta as coisas pela ordem inversa: toma a noção de caso de fronteira como previamente compreendida e usa-a

${ }^{10}$ Williamson (1994) 152: «the inference from ' $p$ and not definitely $p$ ' to 'Definitely $p$ ' is globally valid, as is that from the same premise to 'Not definitely $p$ '». Fine (2008) 113: «The assertion that a given proposition is not definitely the case is $[\ldots]$ presumably incompatible with asserting that it is the case, since their joint assertion would commit one to the contradiction that it is definitely the case and not definitely the case.» 
para fornecer uma análise de ser claramente $F$ como consistindo em ser $F$ e não um caso de fronteira de $F$. Até aqui, não há nenhum problema. $O$ problema começa quando, em seguida, a esta análise, Fine acrescenta uma tese substantiva, segundo a qual, de «x é $F$ » se segue que «x não é um caso de fronteira de $F$ ». É evidente que as duas coisas juntas - a análise e a tese - são suficientes para justificar a regra de introdução de $\Delta$. Pois, se «x é $F$ implica «X não é um caso de fronteira de $F$, então «x é $F$ » também implica « $x$ é $F$ e $x$ não é um caso de fronteira de $F »$; e, pela análise, esta última equivale a «x é claramente $F »$.

Mas, nesta tentativa de justificação da regra, é notório que Fine não nos dá nenhuma razão para apoiar a sua tese de que «x é $F »$ tem como consequência «X não é um caso de fronteira de $F$ ». A relação desta tese com a tese da incompatibilidade é muito estreita. Pois se $x$ fosse um caso de fronteira de $F, \neg \Delta F_{X}$ seria verdadeira. Mas, ao propor aquela tese, Fine está a dizer que a verdade de «X é $F »$ é incompatível com a verdade de «x é um caso de fronteira de $F$ », por isso, incompatível também com a verdade de $\neg \Delta F x$. Mas Fine simplesmente supõe que isto é assim, sem apresentar justificação. Aliás, parece típico dos defensores da tese da incompatibilidade chegarem a este ponto da discussão sem argumentos, como estes exemplos testemunham:

$\ll \ldots$ the assertion that a man is bald, let us say, will surely commit one to his not being a borderline case of a bald man. For how could one sensibly assert that a given man is bald and yet not thereby be willing to deny that he is a borderline case of a bald man? Given that this is so...» (Fine 2008: 120)

«We may hold that no sentence can be true without being determinately true. For how can $a$ be $F$ without being determinately $F$ ? $D p$ and $p$ will then be true in exactly the same situations.» (Keefe 2000: 27)

«I have heard it argued that the introduction of such an operator can serve no point since there is no apparent way whereby a statement could be true without being definitely so. That is undeniable [...].» (Wright 1987: 229)

Dada esta ausência de argumentos, poderíamos tentar nós argumentar contra a tese de Fine do seguinte modo. Se de «x é $F »$ se segue «X

${ }^{11}$ Mas, como assinalámos na nota 9, Crispin Wright dispõe-se a considerar a possibilidade de negar o «inegável» em Wright (2010: 540). 
não é um caso de fronteira de $F$ », então de «x não é $F$ » seguir-se-ia «x não é um caso de fronteira de não- $F$ ». Mas não há nenhuma diferença relevante entre ser um caso de fronteira de $F$ e sê-lo de não- $F$ : qualquer caso de fronteira a respeito de $F$ é-o tanto de $F$ como de não- $F$. E uma vez que o supervalorativista aceita que, para todo o $x$, $x$ é $F$ ou $x$ não é $F$, isso implicaria que não existe realmente vagueza: para todo o $x$, $x$ não é um caso de fronteira de $F$ ou $x$ não é um caso de fronteira de não- $F$; mas como não há diferença conceptual relevante entre estas duas coisas, isso equivaleria a dizer que, quanto à classificação das coisas como $F$ ou não- $F$, não há casos de fronteira. A tese de Fine, juntamente com a aceitação do terceiro excluído, conduz à negação da vagueza.

Contra este argumento, o supervalorativista objectaria que, se uma mesma coisa se segue de «x é $F$ » e de «x não é $F$ », isso não garante que ela se siga da disjunção «x é $F$ ou $x$ não é $F$ ». Ou seja, ele diria que o nosso argumento não é válido, uma vez que usa a regra da eliminação da disjunção precisamente num daqueles casos em que a semântica diz que ela não é correcta ${ }^{12}$. Para o supervalorativista, como já vimos, há disjunções verdadeiras sem nenhum disjunto verdadeiro. Por isso, ele considera que, quando partimos de uma disjunção e consideramos o caso em que um disjunto é verdadeiro e depois o caso em que o outro disjunto é verdadeiro, não considerámos todos os casos possíveis. Por isso, o que se segue daqueles dois casos pode não se seguir da disjunção, pois pode não se seguir do «terceiro caso» (em que nenhum dos disjuntos é verdadeiro).

Julgo que devemos resistir a esta objecção. Comparemo-la com este exemplo apresentado por Shapiro (2006: 82): um pai promete aos seus filhos que, no próximo domingo, se o tempo estiver bom irão ao futebol e, se o tempo não estiver bom, irão ao cinema. Os filhos ficam encantados porque tanto gostam de uma coisa como de outra e, por isso, concluem que vão ter um domingo óptimo. Mas chega domingo, o tempo está na fronteira entre bom e não-bom, e o pai usa isso como justificação para não fazerem nada. Não deverão os filhos sentir-se enganados e protestar que o prometido não foi cumprido? Claro que sim. O facto de o tempo se encontrar indefirior.

${ }^{12}$ Veja-se o contra-exemplo a esta regra apresentado no final da secção ante- 
nido, nem claramente bom nem claramente não bom, significa que a família pode decidir como quiser, de qualquer das duas maneiras - mas eles têm de escolher uma delas. As promessas feitas não permitem a opção de não escolher. A situação seria diferente se a segunda promessa tivesse antes sido «se estiver a chover, iremos ao cinema». Mas, do modo como foram feitas («se o tempo estiver bom, ... e, se não estiver bom, ...»), as promessas cobriram todos os casos possíveis e, por isso, os filhos têm garantido que, se elas forem cumpridas, irão fazer algo de que gostam.

Shapiro usa o exemplo para discutir a semântica de condicionais com antecedentes vagos e consequentes precisos, mas o que aqui sobretudo me interessa é considerar o que acontece quando a família, para que o prometido seja cumprido, escolhe uma das vias. Suponhamos que, apesar de o tempo estar na fronteira entre bom e não-bom, eles decidem contá-lo como bom e vão ao futebol. Esta decisão, que é permitida pelos factos meteorológicos e pelo significado da expressão «tempo bom», não elimina a indefinição do tempo que foi inicialmente observada e consensualmente aceite pelos membros da família, quer dizer, mesmo depois da decisão tomada, o tempo (se não mudar) continua a estar na fronteira entre bom e não-bom. Mas, à luz da decisão tomada, ou no contexto por ela criado, será correcto dizer que o tempo está bom (e por isso eles vão ao futebol), embora não esteja claramente bom.

A objecção supervalorativista ao nosso argumento, ao apelar para um alegado «terceiro caso» em que nenhum dos disjuntos - nem «x é $F »$ nem «x não é $F$ »-é verdadeiro, assemelha-se bastante à estratégia usada pelo pai para tentar escapar ao que havia prometido. Mas não existe «terceiro caso». O que há são diversas maneiras igualmente admissíveis de estabelecer a divisão entre os dois casos possíveis - o positivo e o negativo. E, quando dizemos que elas são «igualmente admissíveis», estamos implicitamente a reconhecer que os casos de fronteira tanto podem ser classificados como positivos como podem ser classificados como negativos - o que é diferente de dizer que eles não são positivos nem negativos. E quando um caso de fronteira é classificado (por exemplo) como positivo, ele não deixa por isso de ser um caso de fronteira. O que está mal no argumento, por conseguinte, não é o uso da eliminação da disjunção (também chamada «demonstração por casos»), mas sim a suposição de que de «x (não) é $F$ » se 
segue logicamente que $x$ não é um caso de fronteira.

Mas o que é seguir-se logicamente? Poderia argumentar-se que esta suposição é aceitável se interpretarmos a relação de consequência lógica do modo como o supervalorativista o faz, quando define a validade dedutiva como preservação da super-verdade. Pois se, quando raciocino a partir de «X é $F$ » o que estou a supor é que «X é $F$ » é super-verdadeira, então é natural que conclua daí que $x$ não é um caso de fronteira (e o mesmo se diria para «x não é $F »)$. Mas o que isto mostra é que temos boas razões para não aceitarmos a definição supervalorativista de validade. Quando, ao raciocinarmos numa linguagem vaga, estabelecemos uma premissa ou propomos uma suposição, para procurarmos que consequências se seguem daí, nem sempre queremos saber o que teria de ser o caso se a premissa ou suposição fosse super-verdadeira. Por vezes raciocinamos a partir de frases vagas (como «O tempo está bom», «António é velho», etc.) e queremos saber o que se segue delas tal como são, e não o que se seguiria se elas fossem super-verdadeiras. Talvez devamos então manter-nos fiéis à noção clássica de validade como preservação da verdade e rejeitar a identificação supervalorativista da verdade com a super-verdade. Diríamos que a super-verdade é uma das maneiras possíveis que uma frase tem de ser verdadeira - e certamente a melhor ou a mais estrita -, mas não é a única. Há frases que são verdadeiras sem serem super-verdadeiras. Se, no caminho para o jogo de futebol, um dos membros da família afirmar que o tempo está bom, ele não estará a violar a norma que diz que só devemos afirmar o que é verdade. No entanto, naquele contexto, «O tempo está bom» não é uma frase super-verdadeira.

Poderíamos recorrer aqui à noção de frase «suficientemente verdadeira» proposta por David Lewis (1979: 244-5). Nas suas breves observações sobre vagueza, Lewis mostra-se favorável ao método das supervalorações. Se Fred é um caso de fronteira de homem careca, a frase «Fred é careca» será verdadeira ou será falsa dependendo de onde colocarmos a linha divisória entre carecas e não-carecas. Existem diversas maneiras igualmente razoáveis de traçar essa linha e, uma vez que não há nada no nosso uso da linguagem que seleccione uma delas em detrimento das outras, devemos considerá-las todas, observando então que «If a sentence is true over the entire range, true no matter how we draw the line, surely we are entitled to treat 
it simply as true». E, em seguida, Lewis escreve:

«But also we treat a sentence more or less as if it is simply true, if it is true over a large enough part of the range of delineations of its vagueness. (For short: if it is true enough.) If a sentence is true enough (according to our beliefs) we are willing to assert it, assent to it without qualification, file it away among our stocks of beliefs, and so forth. [...] When is a sentence true enough? Which are the 'large enough' parts of the range of delineations of its vagueness? This is itself a vague matter. More important for our present purposes, it is something that depends on context. What is true enough on one occasion is not true enough on another. The standards of precision in force are different from one conversation to another, and may change in the course of a single conversation. Austin's "France is hexagonal" is a good example of a sentence that is true enough for many contexts, but not true enough for many others. Under low standards of precision it is acceptable. Raise the standards and it loses its acceptability.»

Esta parece ser uma visão bastante fiel de como realmente usamos uma linguagem vaga. Lewis concorda que a norma da asserção não está ligada à super-verdade. Sem violar a norma, também podemos afirmar frases que são suficientemente verdadeiras (num contexto) sem serem super-verdadeiras (nesse contexto). Além disso, as observações de Lewis apontam para uma possibilidade que, para os objectivos da presente discussão, é especialmente importante: é que o uso das supervalorações talvez não tenha de transportar consigo a tese da incompatibilidade entre ser $F$ e não ser claramente $F$.

É um facto que a teoria supervalorativista standard inclui a tese da incompatibilidade. Vimos já que o supervalorativista não costuma perder muito tempo a procurar razões que a justifiquem. Ela parece-lhe simplesmente evidente. Vimos também que podemos desenvolver algumas linhas de argumentação contra a tese da incompatibilidade e que as objecções supervalorativistas que se lhes opõem podem ser rebatidas. Para terminar esta discussão, tentaremos agora mostrar que há uma incoerência no próprio supervalorativismo, no modo como articula a aceitação da tese da incompatibilidade com a tese de que a verdade é super-verdade e com a definição de super-verdade como verdade em todas as precisões admissíveis da linguagem (enriquecida com o operador «claramente»).

Comecemos com um aspecto do supervalorativismo que foi recentemente apontado por Delia Fara. Pensemos nalguma frase com a seguinte forma lógica: $(p \wedge \neg \Delta p)$. Como sabemos, não há nenhum 
modelo supervalorativista no qual esta frase seja verdadeira (isto é, super-verdadeira). Pelas mesmas razões, uma frase que tenha a forma $(\neg p \wedge \neg \Delta \neg p)$ também não será verdadeira em nenhum modelo supervalorativista. Formemos então a disjunção destas duas frases e designemo-la por $« D F »$. Podemos provar que, para todo o modelo supervalorativista $M$, se $p$ é indeterminada em $M$, então $D F$ é (super-)verdadeira em $M$. Isto é assim, porque, uma vez que $p$ e $\neg p$ são ambas indeterminadas em $M$, tanto $\neg \Delta p$ como $\neg \Delta \neg p$ são super-verdadeiras, ou seja, verdadeiras em todas as precisões de $M^{13}$; então, nas precisões em que $p$ é verdadeira, o primeiro disjunto de $D F$ é verdadeiro e, nas precisões em que $p$ é falsa, o segundo disjunto de $D F$ é verdadeiro - tendo como resultado que $D F$ é verdadeira em todas as precisões e, por isso, super-verdadeira em $M$. $D F$ é um dos casos de disjunção verdadeira sem nenhum disjunto verdadeiro que são característicos da semântica supervalorativista. A explicação habitual para esta anomalia é que ela resulta daquilo a que Fine chama «deslocações de valor de verdade» (truth-value shifts): o disjunto que torna a frase verdadeira desloca-se de umas precisões para as outras de tal maneira que, em qualquer precisão, há sempre um deles que é verdadeiro, mas nenhum disjunto é verdadeiro em todas as pre-

${ }^{13}$ Neste ponto do raciocínio, estamos a aplicar as condições de verdade habitualmente atribuídas a $\Delta$, as quais são análogas às que, no sistema S5 da lógica modal, se atribuem ao operador de necessidade: $\square p$ é verdadeira num mundo possível se e somente se $p$ é verdadeira em todos os mundos possíveis; e $\Delta p$ é verdadeira numa precisão se e somente se $p$ é verdadeira em todas as precisões. Daqui resulta que $\Delta p$ terá sempre o mesmo valor em todas as precisões de cada modelo: $\Delta p$ ou é verdadeira em todas as precisões (super-verdadeira) ou é falsa em todas as precisões (super-falsa), o que faz de $\Delta$ uma noção precisa e bivalente. Estas condições de verdade atribuídas a $\Delta$ parecerão inadequadas se, por causa da vagueza de ordem superior, considerarmos que «claramente velho», «claramente claramente velho», etc., também podem ter casos de fronteira - o que deveria requerer modelos em que $\Delta p, \Delta \Delta p$, etc., fossem indeterminadas. Para superar este problema, Williamson (1994: 158) propõe a introdução de uma relação de admissibilidade entre precisões (em que cada precisão determinaria quais as precisões que, do seu ponto de vista, são admissíveis), sujeita a certas condições. Keefe (2000: 209-11) discute e rejeita a proposta, considerando que $\Delta$ serve para captar a vagueza de primeira ordem, mas não a sua própria vagueza (para isso, precisaríamos de novos recursos expressivos). Alguns autores pensam que a chamada «vagueza de ordem superior» não é um fenómeno real. Neste trabalho, limitamos a nossa atenção à vagueza de primeira ordem. 
cisões. Essa é a explicação geral. Mas, quando se aplica a $D F$, essa explicação torna-se estranha, porque, em $D F$, os disjuntos são ambos frases que, de acordo com a semântica supervalorativista, nunca poderiam ser verdadeiras. Como diz Fara, o supervalorativista parece pensar que «the disjunction of two impossibilities can be true» (2010: 378).

Enquanto Fara foca a sua atenção no comportamento da disjunção, o que nos interessa aqui é sobretudo apontar o fenómeno subjacente que $D F$ traz à luz e que é, muito simplesmente, o seguinte: existem modelos supervalorativistas nos quais frases com a forma $(p \wedge \neg \Delta p)$, que supostamente nunca poderiam ser verdadeiras, são verdadeiras nalgumas precisões. Há uma incoerência no modo como o supervalorativista lida com estas «impossibilidades». A incompatibilidade entre ser de uma maneira e não ser claramente dessa maneira é uma tese filosófica básica aceite pelo supervalorativista. E ele pode alegar que a sua adesão a essa tese está suficientemente representada no sistema formal que propõe. Pois o sistema define uma classe de modelos e não existe, nessa classe, nenhum modelo no qual uma frase com a forma $(p \wedge \neg \Delta p)$ seja super-verdadeira. Mais do que isso, o supervalorativista pode alegar que a tese que sustenta não é apenas formulável na metateoria. Ela também pode ser expressa, na própria linguagem formal do sistema, como $\neg \Delta(p \wedge \neg \Delta p)$. $\mathrm{E} \neg \Delta(p \wedge \neg \Delta p)$ é uma verdade lógica do sistema supervalorativista (super-verdadeira em todos os modelos). Mas, por outro lado, em forte contraste com tudo o que o supervalorativista nos acaba de dizer, também podemos observar que existem modelos supervalorativistas que têm precisões nas quais frases com a forma $(p \wedge \neg \Delta p)$ são verdadeiras. Ora, se estas frases nunca podem ser verdadeiras e se cada precisão corresponde a «uma maneira aceitável de tornar a linguagem precisa» (Keefe 2000: 162), nenhuma precisão deveria avaliá-las como verdadeiras.

As precisões do sistema supervalorativista são interpretações da linguagem vaga - que, como é habitual na teoria dos modelos, incluem um domínio de objectos, uma função que atribui valores às expressões não-lógicas da linguagem e uma valoração das suas frases, simples e compostas. O que significa dizer que essas interpretações têm de ser aceitáveis (ou legítimas, ou admissíveis)? Uma possibilidade é considerar que as interpretações aceitáveis são aquelas que são 
consistentes com as regras semânticas da linguagem ${ }^{14}$. Por exemplo, se há uma regra semântica como «qualquer pessoa mais alta do que uma pessoa alta é também alta», não será aceitável uma interpretação que torne o predicado «alta» preciso de um modo tal que pessoas com $1,83 \mathrm{~m}$ contem como altas, mas pessoas com $1,86 \mathrm{~m}$ não contem como altas. De modo análogo, a regra «nenhuma pessoa alta é também baixa» também exclui como ilegítimas interpretações que não sejam consistentes com ela, ou seja, exclui interpretações que tornem precisos os predicados «alta» e «baixa» de um modo que faça sobrepor as suas extensões. Keefe (2000: 162) dá estes exemplos como ilustrações daquilo a que Fine chama «conexões de penumbra» e, efectivamente, um dos traços característicos do supervalorativismo é a ideia de que as interpretações de uma linguagem vaga têm de respeitar as conexões de penumbra nela existentes: «Penumbral truths are true in all admissible specifications», afirma Keefe (2000: 204). E, segundo Fine, «what distinguishes th[e] operation [of making more precise] from a mere change in meaning is that it preserves truth-value» (1975: 129). Se uma frase tem um valor de verdade antes de qualquer vagueza começar a ser reduzida, ela tem de manter esse valor em todas as interpretações que tornam a linguagem mais precisa: «sentences that are unproblematically true (false) before precisification should stay true (false) afterwards» (Keefe 2000: $162)^{15}$. O que dizer então da frase «Nenhuma pessoa é velha sem o

${ }^{14}$ Williamson (1994: 158): «Supervaluationists often regard admissibility as consistency with the semantic rules of the language. If the rules decide a case, then an admissible interpretation decides it in the same way; it may decide a case when they do not.» Uma vez que a consistência é uma questão de lógica, parece que este critério faria da admissibilidade uma noção precisa - e isso seria problemático em face da vagueza de ordem superior. Williamson diz que poderíamos pensar antes num critério que fosse ele próprio vago: «Admissibility might be conceived as a matter of reasonableness. An interpretation is reasonable if it does not license misuses of the language (from the standpoint of an ordinary understanding of it).»

${ }^{15}$ No entanto, Keefe admite que «conexão de penumbra» não é uma noção precisa: «there may be vagueness over whether certain sentences qualify as penumbral connections» (204-5). E, noutra passagem (a propósito da premissa indutiva do sorites), chega a advogar uma atitude reformista a respeito do que nos parecem ser conexões de penumbra: «we cannot straightforwardly read off cases of penumbral truths from our unreformed intuitions, for the sorites paradox induc- 
ser claramente»?

Dada a sua adesão à tese da incompatibilidade, julgo que o supervalorativista deveria contar a incompatibilidade entre «António é velho» e "António não é claramente velho» como uma conexão de penumbra e contar a frase «Nenhuma pessoa é velha sem o ser claramente» como uma verdade de penumbra. Aquela incompatibilidade ocupa, na sua teoria, um lugar muito mais central do que, por exemplo, a incompatibilidade entre «António é alto»e «António é baixo» (e, como vimos, uma precisão da linguagem na qual estas frases fossem ambas verdadeiras seria considerada inaceitável). Enquanto esta última resulta da relação entre os significados (vagos) de dois predicados não-lógicos, aquela incompatibilidade resulta da relação entre os significados (precisos ou também vagos?) de expressões a que o supervalorativista reconhece o estatuto de expressões lógicas, ou seja, é uma incompatibilidade entre formas lógicas (entre 《_____ é $+++++»$ e «_____ não é claramente $+++++»)$. Nessa medida, assemelha-se mais à incompatibilidade entre «António é alto» e «António não é alto» (e, neste caso, são as próprias regras de valoração das frases, as quais são fixas e comuns a todas as precisões de todos os modelos, que garantem que estas duas frases nunca serão ambas verdadeiras em nenhuma precisão). Mesmo que não lhe queira chamar «conexão de penumbra» (devido ao carácter lógico das expressões essencialmente envolvidas), o supervalorativista deveria querer que a incompatibilidade entre «António é velho»e «António não é claramente velho» fosse respeitada pelas interpretações aceitáveis da linguagem - e que a verdade de «Nenhuma pessoa é velha sem o ser claramente» fosse preservada em todas as precisões. Mas, no seu sistema, há precisões nas quais aquelas duas frases são conjuntamente verdadeiras e esta última frase é falsa. Estas precisões não podem ser excluídas impondo restrições adicionais sobre a admissibilidade das precisões, porque elas são criadas pela própria estrutura lógica do sistema, tal como foi concebido. No entanto, à luz do modo como o próprio supervalorativista compreende a relação entre «ser

tive premise would then count as a penumbral truth [...]. We cannot start with all sentences that are intuitively true (both atomic predications and compound sentences) and then construct the structure of specifications so as to respect all these truths by ensuring they are true on all specifications» (183n14). 
velho» e «ser claramente velho», essas precisões não podem ser vistas como interpretações legítimas da linguagem, consistentes com as suas regras semânticas ou que respeitam os seus significados. Nos termos de Williamson, trata-se de interpretações que permitem usos incorrectos da linguagem.

O supervalorativista poderia tentar defender a sua posição concedendo que a incompatibilidade entre «António é velho»e «António não é claramente velho» não é respeitada por cada uma das precisões da semântica, mas sublinhando que todos os modelos (globalmente considerados) a respeitam. Pois, nos modelos em que «António é velho» é super-verdadeira ou super-falsa, a conjunção «António é velho mas não é claramente velho» é sempre super-falsa; e, nos modelos em que «António é velho» é indeterminada (os quais representam situações em que António é um caso de fronteira), aquela conjunção é também indeterminada. É verdade que, nestes últimos, para que a conjunção seja indeterminada, ela tem de ser falsa numas precisões e verdadeira noutras; por isso, tem de haver precisões nas quais ela é verdadeira - mas isso não tem qualquer significado, é apenas um artefacto do sistema, que não representa nada a respeito do uso correcto da linguagem. É neste sentido que Shapiro (2006: 69) escreve: «For the supervaluationist, completely sharp interpretations are only a technical device used to define super-truth. They need not correspond to actual or even possible uses of the predicates.» E Keefe (2000: 190) concorda: «it is the quantification over all precisifications that captures the meaning of the natural language predicates; the individual precisifications need not.» Mais do que isso, Keefe parece conceder que, tomadas individualmente, algumas precisões podem corresponder ao que seriam usos incorrectos da linguagem: «if [...] a valuation of a language must respect all its meanings, then precisifications should not be called valuations of [a] vague language. But precisifications can still contribute to determining the correct valuation without each being a correct valuation in this sense» (190).

Esta linha de defesa envolve um abandono do modo como antes se caracterizou a noção de admissibilidade, a qual é usada para definir o conjunto de precisões (interpretações admissíveis) que são elementos de um modelo supervalorativista. Pois, enquanto antes se disse que as interpretações admissíveis seriam aquelas que respeitam as verdades de penumbra (mesmo tendo em conta a vagueza desta noção), agora 
já estamos a admitir que as interpretações individuais podem não as respeitar: «we can deny that meaning is preserved through precisification. [...] what matters is respecting truths of meaning in the supervaluationary model as a whole» (Keefe 2000: 190n18). Com este recuo instrumentalista, o método das supervalorações perde grande parte da sua atractividade. Se as precisões individuais não correspondem a possíveis usos correctos da linguagem, mas são apenas «um dispositivo técnico», algo que se passa dentro de uma «caixa preta» e que só nos deve interessar pelos resultados que produz, então, para começar, devemos deixar de usar os conceitos de verdadeiro e de falso para falar do que se passa dentro dessa caixa. E se, quantificando sobre os elementos no interior da caixa, obtivéssemos, ao nível dos modelos, representações correctas da linguagem, que respeitassem as suas «verdades de significado», gostaríamos ainda assim de saber porque é que isso acontece. Se as frases que um modelo determina como super-verdadeiras e como super-falsas coincidissem com as frases que, num contexto de uso, são realmente verdadeiras e falsas, isto é, se a super-verdade fosse um modelo adequado da verdade, deveria haver uma explicação para isso - e uma explicação iluminadora do modo como funciona uma linguagem vaga. Em todo o caso, não parece que o supervalorativista deva estar satisfeito com os resultados produzidos pelo seu sistema de precisões. Pois ele considera que uma frase como «Ninguém é velho sem o ser claramente» é verdadeira em virtude do seu significado, mas o sistema produz modelos (com casos de fronteira de pessoa velha no seu domínio) nos quais ela não é super-verdadeira.

\section{Observações finais}

Concluo que a resposta negativa dada pelo supervalorativismo à pergunta que lancei não é convincente. O supervalorativismo não tem uma boa justificação para essa resposta e vimos, pelo contrário, que a sua adesão à tese da incompatibilidade está envolvida em diversas dificuldades, que revelam aspectos da teoria que falam em seu desfavor. Não retiro daqui nenhum juízo conclusivo a respeito do valor que se deve atribuir à abordagem supervalorativista do fenómeno da vagueza (a qual me continua a parecer, nos seus traços essenciais, uma abordagem interessante). Mas julgo que temos boas razões para 
favorecer antes uma resposta positiva à pergunta inicial, ou seja, para considerar que coisas que não são claramente de uma maneira podem, no entanto, em certos contextos, ser correctamente classificadas como coisas que são dessa maneira - e que é permissível afirmar que elas o são, sem que com isso deixe de ser verdade que elas não são claramente como as estamos a classificar. Dito de outro modo, temos boas razões para considerar que, numa linguagem vaga, há frases que, afirmadas em certos contextos, são verdadeiras, embora não sejam claramente (ou determinadamente) verdadeiras - frases que, como diz Lewis, para os padrões de precisão aceites num contexto conversacional, são suficientemente verdadeiras, mas não mais do que isso. É uma questão em aberto a de saber se a abordagem supervalorativista é adaptável a esta perspectiva de um modo que possa ser descrito, usando a conhecida expressão de Tarski, como «formalmente correcto e materialmente adequado» ${ }^{16}$.

No final da sua monografia, Keefe (2000: 215) recorda as célebres palavras de Aristóteles (que Tarski costumava citar em apoio do esquema descitativo): «Dizer daquilo que é que não é, ou daquilo que não é que é, é falso; enquanto dizer daquilo que é que é, ou daquilo que não é que não é, é verdadeiro.» Keefe pensa que, ao dizer isto, Aristóteles não cobriu todos os casos possíveis e, por isso, pergunta (por exemplo) como é que classificaríamos o «dizer, daquilo que indeterminadamente é, que é». A minha resposta seria: há situações em que isso também é verdadeiro. ${ }^{17}$

Ricardo Santos Universidade de Évora e LanCog Group

${ }^{16}$ McGee e McLaughlin (1995) e Shapiro (2006) trabalham nessa direcção.

${ }^{17}$ Este trabalho foi realizado no âmbito do projecto de investigação Paradoxos: Dedutivos, Indutivos e Práticos (PTDC/FIL/67039/2006), financiado pela Fundação para a Ciência e a Tecnologia e sediado no Instituto de Filosofia da Linguagem FCSH-UNL e na Universidade de Évora. Apresentei versões preparatórias dele no Seminário de Filosofia Analítica da Faculdade de Letras da Universidade de Lisboa, num workshop on vagueness and self-reference que teve lugar na Faculdade de Ciências Sociais e Humanas da Universidade Nova de Lisboa e numa palestra que proferi na Universidade Federal do Rio de Janeiro. Agradeço aos participantes nessas sessões a atenção dispensada e as estimulantes discussões que se seguiram. Agradeço em especial os comentários valiosos que recebi de João Branquinho, Rosanna Keefe, Elia Zardini, Hartry Field, Oswaldo Chateaubriand e Guido Imaguire. 


\section{Referências}

Dietz, Richard e Moruzzi, Sebastiano (eds.). 2010. Cuts and Clouds: Vagueness, Its Nature, and Its Logic. Oxford: Oxford University Press.

Fara, Delia Graff. 2010. Scope Confusions and Unsatisfiable Disjuncts: Two Problems for Supervaluationism. In Cuts and Clouds: Vagueness, Its Nature, and Its Logic, ed. por Dietz e Moruzzi. Oxford: Oxford University Press, pp. 373 382

Fine, Kit. 1975. Vagueness, Truth and Logic. In Theories of Vagueness, ed. por Keefe e Smith. Cambridge: Cambridge University Press, 2000, pp. 119-150.

Fine, Kit. 2008. The Impossibility of Vagueness. Philosophical Perspectives 22, pp. 111-136.

Keefe, Rosanna. 2000. Theories of Vagueness. Cambridge: Cambridge University Press.

Lewis, David. 1979. Scorekeeping in a Language Game. In Philosophical Papers, vol. I, Oxford: Oxford University Press, 1983, pp. 244-245.

McGee, Vann e McLaughlin, Brian. 1995. Distinctions Without a Difference. Southern Journal of Philosophy 33 (supplement), pp. 203-251.

Shapiro, Stewart. 2006. Vaqueness in Context. Oxford: Clarendon Press.

Williamson, Timothy. 1994. Vagueness. Londres e Nova Iorque: Routledge.

Wright, Crispin. 1987. Further Reflections on the Sorites Paradox. In Theories of Vagueness, ed. por Keefe e Smith. Cambridge: Cambridge University Press, 2000.

Wright, Crispin. 2010. The Illusion of Higher-Order Vagueness. In Cuts and Clouds: Vagueness, Its Nature, and Its Logic, ed. por Dietz e Moruzzi. Oxford: Oxford University Press, pp. 523-549. 